Elaine de Jesus Souza

Universidade Federal do Rio Grande do Sul, Porto Alegre, RS, Brasil

Joilson Pereira da Silva

Universidade Federal de Sergipe, São Cristóvão, SE, Brasil

\author{
Claudiene Santos
}

Universidade Federal de Sergipe, São Cristóvão, SE, Brasil

\title{
Representações de docentes acerca da diversidade sexual e homofobia
}

Resumo: As representações sociais que educadores/as possuem acerca da diversidade sexual influenciam a (des)construção de preconceitos na escola. Assim, essa pesquisa qualitativa objetivou analisar as representações sociais de educadores/as do ensino fundamental maior e médio acerca da diversidade sexual e da homofobia. Para tanto, empregou-se o método de análise de conteúdo na modalidade categorial temática. Os resultados obtidos evidenciaram que as representações dos/as educadores/as estão ancoradas em padrões sociais acerca da diversidade sexual, que geram preconceitos sutis e contribuem com a homofobia no ambiente escolar. Portanto, destaca-se a necessidade de (in)formações significativas acerca dessas temáticas, possibilitando aos/às docentes promover ações pedagógicas que contribuam para o reconhecimento da diversidade sexual.

Palavras-chave: Representações; Diversidade Sexual; Preconceitos.

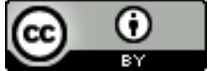

Esta obra está sob licença Creative Commons.

\section{Introdução}

As representações que educadores/as possuem acerca da diversidade sexual e da homofobia podem influenciar a (des)construção de preconceitos e discriminações manifestadas na instituição escolar. Dessa forma, a carência de discussões e (in)formações significativas contribui para o silenciamento e/ou a negação das múltiplas identidades sexuais e de gênero que são invisibilizadas no universo escolar, e, muitas vezes, somente conseguem visibilidade 
através dos insultos e outras manifestações de preconceito. Em decorrência de uma formação docente deficitária (dentre outros motivos) acerca das temáticas sexualidade, gênero e diversidade sexual, muitos/as docentes acabam se omitindo, ao invés de problematizarem a homofobia e todas as expressões de preconceito. Cabe questionar: de que modo as representações sociais acerca da diversidade sexual contribuem para o fortalecimento ou extinção das práticas homofóbicas?

Compreender, (re)conhecer e aceitar o outro com toda a sua multiplicidade constitui uma tarefa complexa para os/ as educadores/as (e toda comunidade escolar), sobretudo porque demanda reflexões críticas acerca de temáticas consideradas polêmicas como sexualidade, gênero e diversidade sexual. Contudo, a busca constante de (in)formações significativas acerca desses temas, a problematização da homofobia e o desenvolvimento de ações pedagógicas podem possibilitar que as representações sociais dos/as docentes sejam condizentes com a desconstrução dos preconceitos e outras violências que marginalizam os indivíduos com identidades sexuais e de gênero distintas do modelo heteronormativo.

Destaca-se que as práticas homofóbicas ocorrem de modo implícito ou explícito no ambiente escolar, sejam na forma do bullying, que engloba piadinhas de cunho preconceituoso feitas entre os/as próprios/as docentes, ou, mesmo, de apelidos pejorativos, ameaças e exclusões que os/as discentes cometem com colegas que diferem dos padrões socialmente estabelecidos para o que se considera masculino e/ou feminino. Torna-se relevante problematizar as convergências entre as representações e os mecanismos heteronormativos, sexistas, heterossexistas, misóginos e machistas que reforçam o padrão heterossexual e a homofobia (Rogério Diniz JUNQUEIRA, 2009). A problematização dos padrões hegemônicos e a construção de subsídios aos/as educadores/as pode ser um caminho para o enfrentamento da homofobia, ao possibilitar o questionamento desses preconceitos incoerentes com o papel da escola, que deveria, justamente, formar cidadãos/ãs críticos/as, que saibam reconhecer as diversidades. Todavia, para Fernando SEFFNER (2009), "a escola pública brasileira foi, e ainda é, largamente utilizada como instrumento de exclusão da cidadania" (p. 28), visto que, embora, na contemporaneidade, a escola viva o desafio de aceitar as diferenças (de classe socioeconômica, raça/etnia, identidades sexuais e de gênero, religiosas, entre outras), em decorrência do histórico de normas, segregações e homogeneizações, ainda (re)produz os preconceitos manifestados na sociedade.

A principal finalidade desse estudo foi analisar as representações sociais de educadores/as da educação 
básica (ensino fundamental maior e ensino médio) acerca da diversidade sexual e da homofobia, visando à compreensão da forma como tais representações podem influenciar e/ou contribuir para a (des)construção de preconceitos e discriminações que perpassam o ambiente escolar. Para tanto, teve como objetivo específico: identificar e descrever os principais conteúdos das representações sociais de educadores/as acerca da diversidade sexual e da homofobia. Cabe adiantar que o lócus dessa pesquisa foi um município de Sergipe onde tais temáticas ainda são pouco exploradas e problematizadas nos cursos de formação docente e, também, nas escolas, o que aponta a relevância da realização de pesquisas no interior do país.

\section{Representações socials, diversidade sexual e homofobia: reconhecimento do não fa- miliar e a desconstrução de preconceitos}

As representações sociais podem constituir o ponto de partida para o (re)conhecimento da diversidade sexual, gênero, sexualidade e homofobia a partir dos processos de ancoragem e objetivação. Tais processos podem possibilitar a compreensão e a familiarização com essa temática, permitindo a desconstrução de crenças e opiniões distorcidas e/ ou arbitrárias acerca das identidades sexuais e de gênero que constituem os preconceitos e discriminações manifestadas através da homofobia.

Nessa direção, destaca-se que as representações sociais constituem sistemas de interpretação que orientam e organizam as comunicações e os comportamentos sociais, pois determinam nossa relação com o mundo e com os outros. $\mathrm{E}$, desse modo, intervêm em diversos processos, tais como o desenvolvimento individual e coletivo, na difusão e assimilação de conhecimentos, bem como na definição de identidades pessoais e sociais, na manifestação dos grupos e nas transformações sociais (Denise JODELET, 1993).

Para Serge MOSCOVICI (2010), transformar palavras, categorias, assuntos, ideias, ou, mesmo, seres e objetos não familiares em algo significativo, usual, próximo, atual e familiar, consiste em uma tarefa complexa, o que aponta para a necessidade de colocar em prática dois mecanismos (ou processos geradores) das representações sociais: a ancoragem e a objetivação.

Nesse contexto, a ancoragem possibilita que a representação seja criada, pois constrói uma rede de significados que dão coerência e aproximação com valores sociais. Já a objetivação permite que algo abstrato seja naturalizado e integrado a realidades concretas, tornando-se compreensível e utilizável na ação sobre os outros e o mundo. Assim, a partir 
desses processos, ocorre a incorporação social das novidades através da classificação e da explicação, modificando visões preexistentes e possibilitando a familiarização do estranho em decorrência da transformação do objeto novo/não familiar (desconhecido e abstrato) em algo familiar (reconhecido e concreto), que faz parte da realidade social (JODELET, 1993; MOSCOVICl, 2010).

As representações sociais são largamente empregadas no estudo dos fenômenos sociais complexos, tais como a questão das diferenças, indo além das atitudes, opiniões e estereótipos. As representações englobam interdependências entre os grupos e contextos socioculturais da realidade em que estão inseridas, por isso nunca poderiam ser "neutras", muito menos entidades estáticas, mas fenômenos sociais dinâmicos, compartilhados por grupos sociais que fornecem conteúdos específicos correspondentes aos seus conhecimentos, crenças, imagens e suas linguagens específicas (Ivana MARKOVÁ, 2008).

As representações sociais não possibilitam somente a integração do estranho às convenções preexistentes, mas, sobretudo, permitem a transformação do familiar. Assim, a renovação dos conteúdos mentais e culturais não envolve apenas a incorporação do novo, mas, também, a modificação de ideias preexistentes, visto que essa renovação requer a transformação do familiar, sua transposição para novos contextos, permitindo uma readequação ao presente, quando é necessário tornar inéditos - estranhar elementos até então familiares. No entanto, na maioria dos estudos de representações, esse processo é de difícil compreensão na prática (Ângela ARRUDA, 2002). Isso remete à questão da diversidade sexual, que aponta reflexões e representações pluralistas e dinâmicas, controvertendo os modelos heteronormativos que, na maioria dos casos, estão ancorados em representações de indivíduos e grupos sociais, como os/as educadores/as.

A diversidade constitui contornos salientes e intrigantes da alteridade, que, com toda sinuosidade, pode tanto afastar quanto aproximar. Nesse sentido, as representações podem ser tanto convencionais e prescritivas, ao expressarem normas socioculturais, quanto construtivas, ao admitirem a reinvenção do sujeito e interpretação do objeto, permitindo, assim, reconhecer a pluralidade e as contradições da vida cotidiana (ARRUDA, 2002; JODELET, 1993; MOSCOVICl, 2010). Dessa forma, as representações sociais podem ser utilizadas para transformar palavras, categorias, assuntos (como a diversidade sexual) em algo familiar e significativo.

A diversidade sexual engloba as múltiplas expressões e vivências de sexualidade e gênero, incluindo as identidades sexuais (homossexuais, heterossexuais e bissexuais) e 
as identidades de gênero, dentre as quais se destacam travestis e transexuais (Guacira Lopes LOURO, 1997).

Segundo Jodelet (1993), as representações sociais impulsionam a diversidade, exaltam o desafio de lidar com a instabilidade e a complexidade. Para Maria Cecília de Souza MINAYO (2008), sendo as representações construídas por meio da linguagem e da comunicação, expressam as contradições das situações reais da vida e marcam o entendimento dos sujeitos, grupos e instituições. Dessa forma, as representações sociais não admitem verdades científicas absolutas e possuem núcleos positivos de transformação e de resistência no modo de compreender a realidade, podendo tanto reproduzir quanto modificar as realidades de determinado segmento social; constituem, portanto, um instrumento eficaz para análise do social e para ações pedagógico-políticas de transformação (MINAYO, 2008). Então, podem ser úteis, principalmente, no estudo da diversidade e na mudança de atitudes preconceituosas. Moscovici (2010) elucida que

[...] todos nossos "preconceitos", sejam nacionais, raciais, geracionais ou quaisquer que alguém tenha, somente podem ser superados pela mudança de nossas representações sociais da cultura, da "natureza humana" e assim p or diante [...]" (p. 66).

Os preconceitos consistem em percepções mentais negativas contra indivíduos e grupos socialmente inferiorizados. Assim, envolvem representações sociais e julgamentos antecipados que possuem componentes cognitivos (referentes às crenças e estereótipos), afetivos (incluindo antipatias e aversões) e disposicionais ou volitivos que resultam em discriminações, ou seja, na materialização dos preconceitos (Marcus Eugênio Oliveira LIMA, 2011 ; Roger Raupp RIOS, 2009).

Entretanto, não é possível determinar um conceito unitário de preconceito, pois este possui várias nuances que envolvem uma conduta rígida frente a diversos objetos e aspectos variáveis de acordo com as representações da pessoa com preconceito. Desse modo, a ausência de experiência e reflexão, requisitos fundamentais para o indivíduo alcançar a compreensão e o (re)conhecimento das diferenças, pode caracterizar ou promover o preconceito (CROCHIK, 2006). Dessa forma, os preconceitos criados em torno da diversidade sexual que caracterizam a homofobia provêm, na maioria dos casos, de conhecimentos parciais que ocasionam representações precipitadas e arbitrárias. Em geral, tais representações são fundamentadas em normas, padrões ou convenções sociais que dificultam a reflexão e a busca de conhecimentos acerca de determinado tema, como a diversidade sexual. 
Distinguem-se duas formas de expressão do preconceito: o manifesto (flagrante) e o sutil. O preconceito manifesto é definido como uma forma mais direta e aberta de expressar atitudes negativas, que inclui elevada rejeição à intimidade e às emoções positivas acerca de indivíduos ou grupos sociais. Já o preconceito sutil representa uma forma mais silenciada, velada ou disfarçada de expressar opiniões contrárias acerca de sujeitos ou grupos. Assim, embora possam manter certo contato e tolerância, os discursos referentes ao preconceito sutil deixam latente que os sujeitos estão agindo de maneira inapropriada e condenável no contexto social, pois não possuem as características e as condutas legitimadas socialmente (LIMA, Jorge VALA, 2004).

Segundo Henrique Caetano NARDI (2012), em um levantamento acerca do preconceito contra as orientações não heterossexuais no Brasil, essa ainda representa um campo de pesquisa recente, visto que a maioria dos estudos foi publicada após o início do programa federal "Brasil sem Homofobia", em 2004. O estudo evidenciou que esse tipo de preconceito possui múltiplas expressões de acordo com o contexto sociocultural do lócus de pesquisa e, embora as discussões estabeleçam uma relação relevante entre orientação sexual e identidade de gênero, tais estudos focalizam as expressões antiquadas/manifestas do preconceito e, não, as versões modernas e sutis da homofobia. Entretanto, esse levantamento apontou que o preconceito contra não heterossexuais no Brasil está relacionado ao sexismo, o preconceito contra as distintas expressões do gênero, que demonstra o não enquadramento aos padrões heteronormativos de masculinidade e feminilidade.

A homofobia consiste em um fenômeno complexo e variado que envolve distintas formas de preconceitos (sutis ou manifestos) e discriminações expressas em diversos âmbitos sociais, por meio de violências psicológicas (agressões verbais, distinções, exclusões, restrições ou preferências) e violências físicas que anulam e prejudicam o reconhecimento e o exercício pleno da cidadania por parte dos indivíduos e/ ou grupos com identidades sexuais e de gênero destoantes do modelo heterossexual. Ressalta-se que a gravidade da homofobia não consiste somente nas práticas de violência física, mas, também, nas manifestações da violência psicológica, presentes nos insultos, nas piadas, na linguagem cotidiana, entre outras manifestações que violam direitos humanos básicos e essenciais de um indivíduo que é julgado inferior apenas por sua identidade sexual e/ou de gênero ser contrária às normas sociais (Daniel BORRILLO, 2009; RIOS, 2009).

Ao compreender a homofobia como preconceitos e/ ou discriminações (e demais violências daí decorrentes) contra indivíduos ou grupos sociais em função de sua identidade 
sexual e/ou de gênero, poderiam ser incluídas neste conceito a lesbofobia, a gayfobia, a transfobia, bifobia, ou seja, a "LGBTfobia" em geral (BRASIL, 2012). Todavia, os diversos movimentos de lésbicas e transgêneros (travestis e transexuais) buscam problematizar a tendência "gaycêntrica" que o uso do termo homofobia pode implicar, procurando se afastar de abordagens individualizantes e despolitizantes centradas nas ideias de "fobia" ou "medo". Assim, são propostas outras denominações que ampliam essa concepção, como "homopreconceito", "heterocentrismo", "homonegatividade", ou que tornam mais visíveis as demais identidades sexuais e de gênero - daí surgiram os termos lesbofobia, transfobia etc. (Marco Aurélio Máximo PRADO; JUNQUEIRA, 201 1), a fim de que possam ser respeitadas suas idiossincrasias.

Ao considerar a amplitude do conceito homofobia, destaca-se que a intensificação dos comportamentos homofóbicos nas escolas ocorre a partir das representações negativas e manifestações de insultos, hostilidades e agressões físicas contra sujeitos destoantes da norma hegemônica, camuflada por um controle invisível da liberdade de expressão, das angústias e pela omissão de identidades não heterossexuais. Para que a homofobia seja combatida na escola, é fundamental que os/as educadores/as adquiram conhecimentos durante a formação inicial e/ou continuada, possibilitando a promoção de ações pedagógicas que contribuam com a problematização e a desconstrução dessa violência (Maria Cristina CAVALEIRO, 2009; LOURO, 2000).

Para Seffner (2013), "[...] a escola é um terreno de experimentação dos modos de ser homem e de ser mulher, e cada vez mais é um terreno de expressão da diversidade de orientação sexual" (p. 154). Contudo, o papel tradicional da escola está direcionado para reprimir as experimentações acerca de sexualidade e gênero, contribuindo para a manutenção das normas sexuais e dos padrões acerca do masculino e do feminino, o que reforça a homofobia e outras formas de preconceito. Nesse sentido, torna-se fundamental problematizar o modo como as relações de gênero e de poder são estabelecidas na sala de aula, bem como investir em programas de combate à homofobia que envolvem as escolas, a família e representantes do movimento de lésbicas, gays, bissexuais e travestis e transexuais/LGBT.

Muitas representações (acerca da diversidade sexual, por exemplo) já chegam prontas, pois são definidas no interior de uma estrutura social e, assim, acabam impondo uma ideologia dominante, isto é, reproduzem um conjunto de ideias e pensamentos hegemônicos em determinado contexto social. Essas representações impostas histórica e socioculturalmente formam um sistema de "teorias espontâneas", pois, de tanto serem ouvidas e justificadas, acabam sendo compre- 
endidas como pensamentos e concepções naturalizadas. Salienta-se, entretanto, que a representação também possui um caráter construtivo, que admite reconstruções (JODELET, 1993). Então, as representações acerca de temas como a diversidade sexual e a homofobia vão sendo construídas a partir de comunicações e ações produzidas ao longo do tempo e das culturas por diversos grupos ou instâncias sociais (como a escola, a família, a igreja, entre outras). Portanto, as representações sociais podem ser reconstruídas em prol da pluralidade e diversidade de sujeitos.

Segundo Sonia Maria Ferreira KOEHLER (2009), tornase indispensável uma mudança de cultura e representações, embora haja dificuldades específicas para desconstruir crenças e normas preestabelecidas acerca do padrão heterossexual. Contudo, visando desestabilizar a homofobia, pode-se (re)conhecer que tais normas acerca das identidades sexuais e de gênero foram construídas historicamente e contribuíram com a produção e manutenção de preconceitos. Além disso, a compreensão da pluralidade de relações, vivências e expressões de sexualidade e gênero que se refletem na própria escola demandaria uma mudança das representações dos/ as educadores/as, sujeitos capazes de intervir nas experiências escolares e transformar essa realidade social.

\section{Metodologia}

Essa pesquisa qualitativa foi realizada em duas escolas públicas (com modalidades de ensino regular e ambas com aproximadamente 350 estudantes) do município sergipano Simão Dias. A escolha desse lócus deve-se à escassez de estudos acerca dessa temática no interior de Sergipe. Foi realizada uma amostragem não probabilística por conveniência com sete professores/as do ensino fundamental maior ( $6^{\circ}$ ao $9^{\circ}$ ano) e dez do ensino médio.

Embora as representações sociais de docentes acerca da diversidade sexual e homofobia tenham sido construídas num contexto específico do interior de Sergipe, este Estado possui uma enorme pluralidade cultural, pois envolve uma amálgama de aspectos (históricos, socioeconômicos, costumes, crenças, tradições e religiões) de todo o País. Dessa maneira, ao analisar as representações de docentes dessas duas escolas, as quais englobam uma multiplicidade de sujeitos com diferenças (sexuais, de gênero, étnicas/raciais, socioeconômicas etc.), visa-se contribuir para reflexões críticas acerca da relevância de promover ações pedagógicas sistemáticas que favoreçam o (re)conhecimento da diversidade sexual e o combate à homofobia.

Neste estudo, desenvolvido após a aprovação do Comitê de Ética e a assinatura, por cada participante, do 
Termo de Consentimento Livre e Esclarecido (Res. 464/12 CNS), foi utilizada a entrevista semiestruturada para coleta das informações, realizada após a aplicação de um questionário com perguntas abertas e fechadas (sobre diversidade sexual, sexualidade, homofobia e a formação docente) elaboradas com base na bibliografia estudada (Nilson Fernandes DINIS, 2012; Ana Flávia do Amaral MADUREIRA, 2007; Jonas Alves da SILVA JUNIOR, 2010; Melani Penna TOSSO, 2012). O questionário envolveu itens referentes aos dados sociodemográficos (idade, sexo, religião, graduação, tempo de atuação docente) dos/as participantes. Entretanto, exceto pela religião, não foram encontradas diferenças significativas nas representações dos/as docentes. Todos os nomes adotados para se referir aos/às docentes são fictícios e seguidos da sigla EF para Ensino Fundamental e EM para o médio.

No questionário, foram inseridas imagens gráficas referentes às identidades sexuais e de gênero não heterossexuais (casal de gays, casal de lésbicas, uma travesti e uma mulher transexual), com o objetivo de compreender de modo acurado as representações dos/as docentes acerca da diversidade sexual. $\mathrm{O}$ uso de imagens possibilita uma apreensão clara e manifesta das representações dos/as docentes, visto que, em conformidade com a própria teoria das representações sociais, torna o objeto de estudo mais concreto, permitindo a revelação das concepções, crenças e pré-julgamentos em torno das identidades sexuais e de gênero ilustradas (SILVA JUNIOR, 2010). As perguntas do questionário, analisadas nesse estudo, foram: 1) O que você entende por: a) Diversidade Sexual; b) Homofobia; 2) Você acredita que a homofobia deve ser considerada crime? Justifique sua resposta. A entrevista teve as seguintes questões norteadoras: 1) Como você avalia a sua formação docente com relação às temáticas sexualidade e diversidade sexual? 2) Quais as suas concepções, vivências e práticas acerca da diversidade sexual e da homofobia?

As informações obtidas foram organizadas por meio da análise de conteúdo definida como um conjunto de técnicas que utiliza procedimentos sistemáticos para descrever os conteúdos de um dado texto e realizar inferências que permitam uma interpretação da realidade fundamentada nos objetivos e na teoria que embasam a pesquisa (Laurence BARDIN, 2011).

Para a análise de conteúdo, foi empregada a modalidade categorial temática, que consiste em desmembrar o texto em unidades de sentido, ou seja, são identificadas as principais opiniões e crenças encontradas nas respostas dos questionários e entrevistas, com o posterior agrupamento dessas unidades em categorias de análise (BARDIN, 2011). As categorias de análise foram construídas a partir da leitura 
das transcrições e da discriminação das unidades de sentido presentes nos relatos dos/as docentes.

\section{Resultados e discussão}

Os resultados obtidos foram agrupados em duas categorias de análise: "Representações acerca da diversidade sexual: a "sutileza" de um preconceito", que engloba as principais concepções e opiniões que constituem os conteúdos das representações dos/as docentes acerca da diversidade sexual; e "Representações acerca da homofobia: conhecimentos parciais e banalização", que inclui as principais crenças e vivências dos/as educadores/as acerca da homofobia na escola.

\section{Representações acerca da diversidade sexual: a "sutileza" de um preconceito}

Nessa categoria, as representações parecem ser positivas, contudo, se revelam reducionistas e ambíguas, pois camuflam concepções, crenças e práticas negativas acerca da diversidade sexual, podendo envolver um tipo de homofobia denominada liberal (sutil) que se refere à aparente aceitação das diferenças sexuais. Ademais, a maioria dos/ as docentes evidenciou a falta de (in)formações significativas acerca das temáticas diversidade sexual e sexualidade durante a formação inicial e continuada, o que pode ser notado pelo uso constante de termos inadequados como "escolha e opção sexual".

Nas entrevistas, quando foram indagados/as sobre a avaliação da formação docente referente à temática da diversidade sexual, todos/as os/as educadores/as enfatizaram a carência ou abordagem superficial e insuficiente acerca da sexualidade e diversidade sexual na formação docente inicial:

Então, a nossa formação acadêmica não ajuda muito pra gente estar lidando com essas situações cotidianas na escola. (Prof. ${ }^{a}$ Roberta - EF; 41 anos, católica, leciona Matemática há 21 anos)

[...] só na disciplina de psicologia, mas nada que eu pudesse ter memória não, foi algo bem superficial, você não vê bem trabalhada não [...]. (Prof. a Ariella - EM; 42 anos, católica, leciona Português há 16 anos)

A imprescindibilidade da inclusão dessas temáticas nos currículos dos cursos de licenciatura foi salientada pelos/ as docentes, e essa carência na formação inicial constitui um dos grandes responsáveis pelos pré-conceitos e estereótipos criados em torno da sexualidade e da diversidade sexual. Em muitos casos, por não terem adquirido tais conhecimentos, muitos/as educadores/as evitam abordar esses 
temas em sala de aula, contribuindo, de forma direta e/ou indireta, para a manutenção dos preconceitos sutis ou manifestos, mitos, tabus e violências como a homofobia.

Cabe ressaltar que o preconceito sutil caracteriza-se por um discurso camuflado ou velado que encobre os reais sentimentos e crenças acerca de determinado indivíduo ou grupo social, não obstante essa sutileza e tolerância acabem perpetuando as desigualdades sociais (Alessandra Ramos Demito FLEURY, Ana Raquel Rosas TORRES, 2010; LIMA, VALA, 2004; SILVA JUNIOR, 2010).

É justamente porque quase ninguém admite ter preconceitos que, com frequência, ouvimos as pessoas dizerem: "Não tenho preconceito, mas não gosto de homossexuais". O que evidencia contradições, pois, embora quase ninguém assuma ter preconceitos, já que esse termo remete à ignorância e à intolerância, os discursos revelam os pré-julgamentos, ainda que expressos de modo sutil ou latente (FLEURY; TORRES, 2010).

Embora os/as educadores/as tenham afirmado que respeitam a diversidade sexual e não tenham admitido qualquer forma de preconceito contra indivíduos que destoam do modelo heteronormativo, pôde-se vislumbrar, em seus relatos, a partir da análise das representações sociais, alguns indícios de homofobia liberal (ou sutil) expressos de forma camuflada e negada (BORRILLO, 2010).

As representações, enunciadas ao questionamento sobre o que os/as docentes entendiam por diversidade sexual, apontaram a ideia de "escolha ou opção" em seis respostas, que podem ser exemplificadas abaixo:

Liberdade de expressar o desejo e opção sexual. (Prof. Antônio - EF; 33 anos, católico, leciona Ciências há 14 anos)

Diferença sexual, oposição, multiplicidade ou até mesmo contradição entre pessoas, seres. (Prof. ${ }^{a}$ Camila - EF; 23 anos, católica, leciona Português há 2 anos)

Opções sexuais variadas. (Prof. ${ }^{a}$ Vanuza - EM; 31 anos, católica, leciona Química há 7 anos)

A pluralidade de opções sexuais que o indivíduo pode exercer. (Prof. Raul - EM; 31 anos, católico, leciona Geografia há 9 anos)

Nas entrevistas, ao questionar os/as professores/as sobre as concepções, vivências e práticas acerca da diversidade sexual, também foram expressas, em sete falas, representações da diversidade sexual como "escolha" ou "opção sexual". Essa representação das identidades sexuais como "escolhas ou opções" remete ao pouco conhecimento sobre a constituição das identidades sexuais, alicerçado em uma forma de preconceito sutil, uma das faces dos julgamentos 
antecipados advindos das normas, características e papéis impostos socialmente aos indivíduos, mas de forma latente e camuflada (BORRILLO, 2009; CROCHIK, 2006; LIMA, 2011; RIOS, 2009; SILVA JUNIOR, 2010). Isso é perceptível nos relatos abaixo:

Desde quando o outro escolhe ser o que naturalmente não era pra ser. A gente tem que haver [sic] o respeito. Porque tem o livre-arbítrio todo mundo é livre pra suas escolhas. [...]. (Prof. a Roberta - EF; 41 anos, católica, leciona Matemática há 21 anos)

[...] a definição de diversidade sexual seria o fato das pessoas terem liberdade de escolher a opção sexual que elas desejam. (Prof. Denis - EM; 22 anos, evangélico, leciona Física há 4 meses)

A primeira docente compreende a diversidade sexual como algo contrário à natureza ou como uma escolha ou opção e não como uma construção social que envolve múltiplos e complexos fatores. A diversidade sexual inclui as diferentes práticas, vivências e expressões de sexualidade e gênero construídas no decorrer da vida humana a partir de aspectos históricos e socioculturais, e não por simples escolha, influência ou determinismos biológicos (JUNQUEIRA, 2009; Luciana KAMEL \& Cristina PIMENTA, 2008; LOURO, 2000; 1997).

Nas sociedades contemporâneas, os indivíduos são diariamente confrontados com uma gama de informações, então as 'novas' questões (como a diversidade sexual) que surgem no âmbito social, por afetarem de algum modo suas representações sociais através dos mecanismos de ancoragem e objetivação, precisam ser compreendidas, visando a uma aproximação com aquilo que já é familiar, utilizando palavras que fazem parte do repertório. Nos diálogos cotidianos, em casa, no trabalho, com os/as amigos/as, os sujeitos manifestam suas crenças sobre tais novidades procurando explicações, fazendo julgamentos e tomando posições. Dessa forma, estas interações sociais vão produzindo "universos consensuais" a partir das comunicações entre os indivíduos ou grupos que alicerçam a construção de novas representações ou a reafirmação das normas que as determinam (Alda Judith ALVES-MAZZOTTI, 2008).

Nesse contexto, podem ser mantidas convenções e normas sexuais e de gênero que, a partir do emprego de termos inadequados e pré-julgamentos, ocasionam diversos tipos de preconceitos. Logo, na sociedade contemporânea, foram produzidas novas formas de expressão do preconceito, de modo que ele passou a ocorrer sem, aparentemente, "ferir o princípio da igualdade", o que pode dar a impressão ingênua de que o preconceito estivesse de fato diminuindo, quando, na verdade, está assumindo facetas mais sutis e menos flagrantes (FLEURY; TORRES, 2010). Infere-se, assim, o

530 Estudos Feministas, Florianópolis, 25(2): 519-544, maio-agosto/2017 
desenvolvimento de uma forma de preconceito sutil, que se expressa de modo camuflado, pois, apesar de não concordar ou aceitar determinadas diferenças, predomina um discurso politicamente correto, baseado na ideia do respeito e do livre-arbítrio (CROCHIK, 2006; SILVA JUNIOR, 2010).

É importante entender que o termo "opção sexual" deveria ser substituído por identidade sexual, pois o desejo afetivo-sexual não é uma opção consciente. Por conseguinte, as identidades sexuais e de gênero resultam de um processo profundo que envolve diversos fatores sociais, culturais, emocionais, entre outros (Ricardo HENRIQUES, Maria Elisa Almeida BRANDT, JUNQUEIRA, Adelaide CHAMUSCA, 2007; LOURO, 1997).

Destarte, torna-se fundamental desconstruir essa representação de "opção sexual" que fortalece uma forma de preconceito sutil disseminado na sociedade em substituição ao preconceito manifesto (SILVA JUNIOR, 2010). No entanto, denota-se que, no senso comum, a representação de 'opção sexual' expressa por algumas pessoas pode significar contraposição ao suposto determinismo natural heterossexual.

Na questão referente às imagens gráficas de um casal de gays, casal de lésbicas, uma travesti e uma mulher transexual, desvelou-se o preconceito sutil relacionado com a homofobia liberal. Embora os relatos ressaltem a importância do respeito ao outro, a aceitação da diversidade sexual é feita com ressalvas que asseguram a manutenção das características heteronormativas no espaço público (BORRILLO, 2009; TOSSO, 2012).

Em consenso, com relação às imagens referentes ao casal de gays e ao de lésbicas, cinco educadores/as marcaram as mesmas alternativas na questão e apresentaram justificativas muito semelhantes, revelando a presença de receios quanto à exposição pública de gestos afetivos entre indivíduos do mesmo sexo:

Até aceito, mas depende do lugar. Devido às atitudes preconceituosas de muitos na sociedade estar vivenciando pode ser motivo para ridicularizar. (Prof. Antônio - EF; 33 anos, católico, leciona Ciências há 14 anos)

Até aceito, mas depende do lugar. Certo é "normal", porém devemos nos comportar, em relação a lugares e pessoas presentes, postura sempre. (Prof. ${ }^{a}$ Camila EF; 23 anos, católica, leciona Português há 2 anos)

Até aceito, mas depende do lugar. É aceitável como qualquer casal, só depende da forma como é

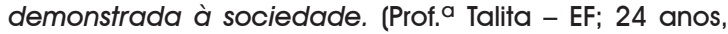
católica, leciona Educação Física há 4 anos)

Até aceito, mas depende do lugar. É normal, mas quanto mais reservado, melhor. (Prof. Elias - EM; 43 anos, católico; leciona Matemática há mais de 20 anos) 
${ }^{1}$ Em 1973, a Associação Psiquiátrica Americana (APA), após compreender que a homossexualidade não consiste em doença, desvio ou perversão, a excluiu do seu Manual de Diagnóstico e Estatística de Distúrbios Mentais (DSM). No Brasil, em fevereiro de 1985, o Conselho Federal de Medicina deixou de considerar a homossexualidade como doença, distúrbio ou perversão. E, em 1990, a Organização Mundial da Saúde (OMS) excluiu a homossexualidade do Código Internacional de Doenças (CID) (HENRIQUES et al., 2007).
Até aceito, mas depende do lugar. É estranho, ainda não me acostumei com esse tipo de imagem. (Prof. Diego - EM; 27 anos, evangélico; leciona Biologia há 4 anos)

Em meio a essas representações, é desvelada a presença camuflada da homofobia liberal, que almeja garantir o respeito pela intimidade através de expressões privadas sem permitir o reconhecimento social dos indivíduos homossexuais. Coloca-se, então, o direito à liberdade em divergência, visto que a liberdade homossexual exigiria somente o respeito por sua eventual manifestação e não seria um direito assegurado pelo Estado. É desse modo que, para a ideologia liberal, o Estado deveria simplesmente permitir o exercício da liberdade homossexual, exclusivamente, nos limites da intimidade, em contrapartida com relação aos sujeitos heterossexuais, sua vida íntima (de casal e família), superando amplamente o âmbito privado, alcançando o dever e a garantia estatal do reconhecimento e da proteção (BORRILLO, 2010).

Essas representações indicam, também, além da homofobia liberal, conhecimentos parciais acerca das identidades sexuais e de gênero revelado pelo uso do termo homossexualismo,' que foi bastante empregado nos relatos dos/as docentes e precisa ser esclarecido e atualizado, pois corrobora os diversos tipos de preconceitos que alicerçam a homofobia.

Com relação às imagens ilustrativas de uma travesti e uma mulher transexual, respectivamente, em quatro respostas as representações expressaram de modo implícito o preconceito, deixando subentendida a presença da norma e de conhecimentos parciais sobre travestilidade e transexualidade:

Até aceito, mas depende do lugar. Devido aos costumes tradicionais da sociedade, porém vejo que muitos extrapolam em suas atitudes. [...] A opção e a vida particular não devem interferir, pois tem liberdade de expressão. (Prof. Antônio - EF; 33 anos, católico; leciona Ciências há 14 anos)

Até aceito, mas depende do lugar; É normal, mas quanto mais reservado, melhor. (Prof. Elias - EM; 43 anos, católico; leciona Matemática há mais de 20 anos)

É normal. Hoje em dia é normal nos depararmos com essas situações. (Prof. Lúcio - EF; 30 anos, católico; leciona Geografia há 4 anos)

Outras reações: Acho engraçado! A cultura do carnaval e o jeito irreverente do travesti são engraçados. (Prof. Rafael - EM; 32 anos, espírita; leciona Educação Física há 2 anos)

Essa dificuldade em reconhecer as múltiplas sexualidades e desestabilizar a lógica binária do gênero contribui 
significativamente para a marginalização dos indivíduos que não ocupam nenhum dos dois lados dessa polaridade. Desse modo, as representações normativas em torno dos/as travestis e transexuais acabam nutrindo preconceitos, pois reforçam a episteme dominante que pretende excluir da esfera social todas as formas de ambiguidade e atravessamento das fronteiras de gênero e de sexualidade. Contudo, de forma paradoxal, esses indivíduos "marginalizados" continuam sendo necessários, pois servem para delimitar os contornos daqueles que se enquadram nas normas (LOURO, 2009).

Os conteúdos acima demonstram que as representações de muitos/as docentes continuam ancoradas em convenções sociais e religiosas que insistem na imposição da heteronormatividade. Então, a heterossexualidade é tida como a única identidade sexual legítima e que detém a garantia plena da cidadania, pois pode ser reconhecida na esfera pública. A ancoragem nesse quadro de referência acaba dificultando a efetiva objetivação das representações novas (em torno da diversidade sexual), pois "o novo", ao invés de transformar antigas crenças, termina sendo incorporado e utilizado para reafirmar a relevância da manutenção das normas sociais, e, assim, as identidades não heterossexuais continuam sendo marginalizadas (JUNQUEIRA, 2009; LOURO, 2009; MOSCOVICI, 2010).

Desse modo, os protótipos e discursos vigorantes que ditam regras sobre as sexualidades devem ser problematizados a partir do questionamento e análise crítica dos padrões hegemônicos, visando promover uma reeducação sexual que reconheça a pluralidade de sujeitos, valores e condutas, e desconstruir representações fundamentadas em ditames sociais, o que demanda desnudar-se das crenças, interditos, doutrinas e preconceitos (LOURO, 2009; SILVA JUNIOR, 2010).

\section{Representações acerca da homofobia: conhecimentos parciais e banalização}

As representações dos/as educadores/as acerca da homofobia evidenciaram contradições, pois apesar de não visibilizarem a amplitude dessa violência, revelaram algumas concepções mais amplas, que incluem as práticas de homofobia indireta ou sutil, e outras reducionistas, como se a homofobia incluísse somente a aversão ou preconceito contra os homossexuais. Isso pode ser explicado pelo entendimento literal do termo e pela falta de conhecimentos acerca desses temas durante e após a graduação.

No questionário, quando foi perguntado: "O que você entende por homofobia?", as concepções de quinze docentes revelaram conhecimentos parciais e representações reducionistas acerca desse tema. A seguir, alguns exemplos: 
Aversão a homossexuais. (Prof. ${ }^{a}$ Roberta - EF; 41 anos, católica, leciona Matemática há 21 anos)

Medo de assumir o que realmente é, devido ao preconceito da família e da própria sociedade. (Prof. Antônio EF; 33 anos, católico; leciona Ciências há 14 anos)

Medo do semelhante, atualmente termo usado para descrever o preconceito e a violência contra os homossexuais. (Prof. Samuel - EF; 30 anos, católico, leciona Inglês há 5 anos)

Preconceito contra homossexuais, aversão ou discriminação seja de formas sutis ou não. (Prof. ${ }^{a}$ Claudia - EF; 49 anos, evangélica, leciona História há 23 anos)

Sentimentos e/ou atitudes de aversão aos homossexuais. (Prof. Diego - EM; 27 anos, evangélico; leciona Biologia há 4 anos)

Sentimento torpe da homossexualidade. (Prof. ${ }^{a}$ Júlia EM; 43 anos, religião da Floresta; leciona Sociologia há 10 anos)

Agressão física ou verbal a uma pessoa que fez a opção sexual por outra do mesmo sexo. (Prof. Raul - EM; 31 anos, católico, leciona Geografia há 9 anos)

Intolerância e repugnação [sic] a pessoas do mesmo sexo no contato afetivo. (Prof. Rafael - EM; 32 anos, espírita; leciona Educação Física há 2 anos)

É necessário esclarecer que, embora o conceito de homofobia tenha sido empregado, inicialmente, para se referir a um conjunto de emoções negativas (aversão, desprezo, ódio ou medo) em relação à homossexualidade, essa representação foi ampliada para englobar as múltiplas faces da violência homofóbica, visto que entendê-lo daquela forma limitada implica pensar o seu enfrentamento somente a partir de medidas direcionadas a minimizar os efeitos de sentimentos e atitudes de "indivíduos" ou "grupos homofóbicos", deixando de lado as instituições que nada teriam a ver com isso. Contudo, a homofobia deveria ser representada como um fenômeno psicológico e social que está ancorado nas complexas relações estabelecidas entre uma estrutura psíquica e uma organização social normativa que considera a heterossexualidade como ideal no âmbito afetivo-sexual. Com efeito, enseja-se que outras manifestações menos grosseiras, mas insidiosas, exerçam suas violências cotidianamente, pois esta outra face de homofobia mais eufemística e de cunho social ancora-se na atitude de desdém constitutiva de uma forma habitual de apreender e de categorizar o outro (BORRILLO, 2009; 2010; JUNQUEIRA, 2009), ou seja, uma forma normatizante e negativa de representar as diferenças, nesse caso, a diversidade sexual.

534 Estudos Feministas, Florianópolis, 25(2): 519-544, maio-agosto/2017 
A partir dessa explanação, salienta-se que o conceito de homofobia não se refere exclusivamente à rejeição aos homossexuais, mas, também, ao não reconhecimento e inclusão de sujeitos bissexuais, travestis, transexuais, que tenham essa identidade sexual e de gênero ou somente porque são pré-julgados pelo não enquadramento ao modelo heteronormativo (TOSSO, 2012).

As representações dos/as docentes denotam uma variedade de pensamentos, crenças e ideias préestabelecidas em torno da homofobia. Nota-se, assim, desde a presença de normatizações em torno desse conceito, até um olhar mais atento e abrangente, confirmando que as representações constituem um fenômeno psicossocial que está ancorado tanto na esfera pública quanto nos processos que possibilitam aos indivíduos construir suas identidades. Dessa forma, as representações criam símbolos e se abrem para a diversidade através dos núcleos positivos de transformação que decorrem da efetiva objetivação do conhecimento "novo", ou, em contraponto, ancoram-se em núcleos resistentes à compreensão da realidade além das normas. É desse modo que a visão dos grupos sociais acerca de determinado objeto (nesse caso, a homofobia) expressa as contradições em que as representações sociais foram construídas (Sandra JOVCHELOVITCH, 2008; MINAYO, 2008).

Nas entrevistas, quando indagados/as acerca de suas concepções, vivências e práticas acerca da diversidade sexual e da homofobia, os/as docentes revelaram as seguintes concepções, opiniões e crenças acerca da homofobia:

É o preconceito que se tem contra o homossexualismo, né? É aquela aversão que as pessoas têm contra a prá-

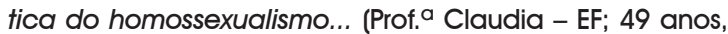
evangélica, leciona História há 23 anos)

[...] acho que a homofobia é mais um tipo de preconceito, assim como tem com os negros, mulheres, deficientes. Pra mim é um preconceito como outro mesmo qualquer. É... mesmo porque a gente tem agressões a negros, a nordestinos, bem como a homossexuais. (Prof. Samuel - EF; 30 anos, católico, leciona Inglês há 5 anos)

Homofobia é quando uma pessoa rejeita, tem aversão aos homossexuais. E dentro da escola, essas brincadeiras são piores até do que uma agressão física que machuca, mas depois cicatriza com o tempo, mas a verbal é pro resto da vida fica na sua consciência (Prof.a Talita - EF; 24 anos, católica; leciona Educação Física há 4 anos)

A homofobia é [...] o preconceito com as pessoas homossexuais [...] sou uma pessoa católica e concordo em eles adotarem um filho, porém não concordo que eles casem. É um extenso assunto, extensos problemas, 
entendeu? Que eu concordo e não concordo. (Prof. a Camila - EF; 23 anos, católica, leciona Português há 2 anos)

[...] o homofóbico é aquele ser que não aceita a homossexualidade, que discrimina, tem receios de estar em contato com homossexuais, que descaracteriza a homossexualidade [...]. (Prof. Elias - EM; 43 anos, católico; leciona Matemática há mais de 20 anos)

[...] o limite da homofobia é humilhar, destratar uma pessoa, agir com violência, excluir a pessoa por ser homossexual [...]. (Prof. Afonso - EM; 32 anos, agnóstico; leciona Inglês há 7 anos)

[...] a homofobia é justamente isso; é você enxergar o próximo como alguém que está cometendo algo errado [...]. (Prof. Denis - EM; 22 anos, evangélico, leciona Física há 4 meses)

Os relatos acima abrangem representações reducionistas acerca da homofobia, que foram apreendidas, também, nos questionários, visto que, de modo geral, a maioria dos/as educadores/as compreende a homofobia somente na dimensão do preconceito, aversão e rejeição aos homossexuais. Ainda que a questão das agressões verbais também tenha sido apontada em um relato, é visível que a representação literal do termo homofobia ainda prevalece devido à falta de (in)formações atualizadas acerca de um tema tão relevante para o âmbito escolar. O uso de termos inadequados ("homossexualismo", "condição", "opção sexual") foi recorrente nas falas dos/as docentes, o que desvela uma deficiência na atualização quanto aos termos, na formação inicial e continuada. Além disso, a influência da religião também pôde ser vislumbrada nas representações.

Apesar da mudança de tom, a homofobia enraizada nas crenças e dogmas religiosos ainda subsiste, contudo, ao invés de lançar os sodomitas na fogueira, agora, se considera a complacência, a compaixão e, até, a "tolerância", para que, na melhor das hipóteses, os/as homossexuais (e outros que fogem às normas) sejam "curados/as" ou possam viver na abstinência (BORRILLO, 2010). Assim, a hostilidade da Igreja e de outras instâncias sociais (inclusive a escola) acerca da diversidade sexual é, atualmente, muito mais sutil, visto que as práticas homofóbicas não se referem somente à condenação ou rejeição dos homossexuais, mas promovem a indiferença subjacente ao liberalismo contemporâneo. Nesse ponto se ancora a homofobia cognitiva ou social referente à marginalização da diversidade sexual e a manutenção das diferenças de direitos humanos que não são problematizadas, e a homofobia liberal também é lembrada como uma forma de privação da liberdade de

536 Estudos Feministas, Florianópolis, 25(2): 519-544, maio-agosto/2017 
expressão sexual no âmbito público (BORRILLO, 2010; TOSSO, 2012).

Acerca das vivências e práticas relativas à homofobia, dez docentes revelaram ter presenciado situações de preconceitos e, sobretudo, agressões psicológicas. No entanto, alguns/mas professores/as não consideram os insultos e apelidos pejorativos como uma prática homofóbica, o que ocorre devido à visão restrita de homofobia como agressão física, e, por vezes, a banalização das violências verbais e psicológicas ou, em alguns casos, até a participação em ações preconceituosas, nomeadas como "brincadeirinhas". Entretanto, aponta-se que a formação religiosa também pode contribuir para a manutenção da homofobia e de outras formas de preconceitos que permeiam a escola e toda a sociedade. Tais representações podem ser notadas nos relatos abaixo:

[...] Já vi insultos, humilhações, já me deparei com essas situações diariamente. Em questão de diversidade sexual, a homofobia e o preconceito, que nos deparamos diariamente com a sociedade, infelizmente. (Prof. ${ }^{a}$ Camila EF; 23 anos, católica, leciona Português há 2 anos)

A gente sempre presencia, né? É... um assunto que a gente acaba, às vezes, brincando, né? Entre aspas. Mas sempre tem o preconceito por trás. Até eu mesmo, às vezes, brinco. (Prof. Samuel - EF; 30 anos, católico, leciona Inglês há 5 anos)

[Casos] de homofobia não. A gente vê, às vezes, alguns meninos que demonstram [...] ter um lado mais afeminado e os coleguinhas: "Ah, é viado!", mas algum caso esporádico em sala de aula, durante intervalo. (Prof. ${ }^{a}$ Roberta-EF; 41 anos, católica, leciona Matemática há 21 anos)

[...] essas coisinhas acabam acontecendo, de piadinhas, apelidinhos. Aí na hora você tem que ser o educador e fazer respeitar essas diferenças na sala de aula, mas... quando percebo, costumo trabalhar com isso. (Prof. a Amanda - EM; 25 anos, católica, leciona História há 8 anos)

No gesto motor quando a criança vai executar, o colega faz uma chacota e imita de uma forma pejorativa, acentuando o lado afeminado, várias vezes falam: "ah olhe como ele saca, olhe a mãozinha dele, ih lá vem a bicha". (Prof. Rafael - EM; 32 anos, espírita; leciona Educação Física há 2 anos)

Um menino da sala, que os colegas julgam como homossexual [...] usaram um termo pejorativo: "Que nada, seu viadinho!" E na hora, confesso que não soube o que fazer, como lidar com a situação [...]. (Prof. Dênis - EM; 22 anos, evangélico, leciona Física há 4 meses) 
Discriminados com violência, são insultados com apelidos pejorativos. Um aluno falou pra mim que vinha para escola e alguns colegas chamando ele de: "Viado! Viado!". Dessa forma, por colegas da escola, um outro foi surrado o ano passado no pátio da escola. (Prof. a Julia - EM; 43 anos, religião da Floresta; leciona Sociologia há 10 anos)

Embora a homofobia constitua uma violência psicológica e social, a maioria das pessoas ainda não a representa como tal. Contudo, quando tal violência é interiorizada sob a forma de injúrias, afirmações desdenhosas, insultos, condenações morais ou atitudes compassivas, há diversas consequências na vida de jovens que dela são alvos. Muitos/ as jovens sofrem distúrbios psicológicos, como sentimentos de culpa, ansiedade, vergonha, depressão, o que leva à exclusão social e, em alguns casos, comete-se até suicídio. Desse modo, a interação entre os níveis psicológico e o social precisaria ser questionada para se compreender melhor os elementos constantes que facilitam, estimulam ou banalizam a homofobia (BORRILLO, 2010).

Em contraponto, quando os/as docentes foram indagados/as se a homofobia deve ser considerada crime, dezesseis (dos 17) afirmaram que sim, de modo geral, com justificativa na importância da liberdade e do respeito suprimidos pela homofobia através dos preconceitos e discriminações que causam sofrimentos físicos e psicológicos aos indivíduos não heterossexuais. Contudo, em um desses relatos, houve contradição, ao apontar a necessidade de uma definição precisa da homofobia para torná-la crime. Ademais, um docente mostrou-se contrário à criação de uma lei específica para criminalização da homofobia.

Sim. Pois devido termos [sic] uma sociedade muito preconceituosa, faz com que evite o máximo esse tipo de atitude. (Prof. Antônio - EF; 33 anos, católico; leciona Ciências há 14 anos)

Sim. Devemos respeitar todos, independente da orientação sexual. (Prof. ${ }^{a}$ Camila - EF; 23 anos, católica, leciona Português há 2 anos)

Sim. A liberdade do homem é algo sagrado e essencial para a vida, ninguém tem o direito de interferir na escolha do outro, usando da violência seja física ou psicológica. (Prof. ${ }^{a}$ Claudia - EF; 49 anos, evangélica, leciona História há 23 anos)

Sim. Qualquer tipo de preconceito e desrespeito deve ser considerado crime, já que somos todos iguais perante as leis. (Prof. ${ }^{a}$ Vanuza - EM; 31 anos, católica; leciona Química há 7 anos)

Acredito que todo tipo de agressão ou desrespeito ao outro enquanto ser humano, não deixa de ser um crime.

538 Estudos Feministas, Florianópolis, 25(2): 519-544, maio-agosto/2017 
(Prof. ${ }^{a}$ Ariella - EM; 42 anos, católica, leciona Português há 16 anos)

Sim, caso outras fobias também sejam criminalizadas. Antes de mais nada, é importante defini-la com precisão. (Prof. Denis - EM; 22 anos, evangélico, leciona Física há 4 meses)

Não como categoria específica de crime, pois qualquer tipo de atitude violenta, preconceituosa, degradante, humilhante com qualquer ser humano deve ser crime. Não é necessário criar categorias de seres humanos, pois amplia a separação. (Prof. Diego - EM; 27 anos, evangélico; leciona Biologia há 4 anos)

A homofobia envolve diferentes práticas de preconceito e discriminação manifestadas em diversos âmbitos sociais, por meio de segregações, desigualdades e privações que prejudicam o reconhecimento e o exercício pleno da cidadania LGBT. Portanto, a homofobia representa um ato violento e criminoso não somente quando envolve agressões físicas, mas, também, à medida que viola direitos sexuais e humanos de um indivíduo julgado inferior apenas por sua identidade sexual ser divergente das normas sociais impostas de modo arbitrário (BORRILLO, 2009; RIOS, 2009).

Nessa perspectiva, à

[...] semelhança de qualquer outra forma de intolerância, a homofobia articula-se em torno de emoções (crenças, preconceitos, convicções, fantasmas...), de condutas (atos, práticas, procedimentos, leis...) e de um dispositivo ideológico (teorias, mitos, doutrinas, argumentos de autoridade...) (BORRILLO, 2010, p. 34-35).

Ressalta-se, assim, que a homofobia "[...] está tão arraigada na educação que, para superá-la, impõe-se um verdadeiro exercício de desconstrução de nossas categorias cognitivas [...]" (BORRILLO, 2010, p. 87).

Nessa direção, as representações sociais podem favorecer o reconhecimento da diversidade sexual e a desestabilização da homofobia, ao possibilitar, por meio dos processos de ancoragem e objetivação, a (re)construção de concepções, crenças e práticas voltadas para a pluralidade. Para tanto, é necessário um árduo processo de desconstrução de representações alicerçadas em normas sociais e preconceitos, que demandaria desconstruir o pensamento arcaico e conservador para ancorar o novo e desafiador.

\section{Considerações finais}

Um dos principais empecilhos para inclusão da diversi-dade sexual na escola consiste na falta de (in)formações, visto que a maioria dos cursos de graduação 
e pós-graduação não insere, de modo significativo, as temáticas da sexualidade. Assim, diante das representações sociais reveladas nos relatos dos/as docentes acerca da diversidade sexual e da homofobia, cabe deixar uma indagação: Como incluir a diversidade e desconstruir preconceitos sem (in)formação significativa?

Em virtude das lacunas na formação docente inicial e continuada e das normatizações socioculturais e religiosas, as representações acerca da diversidade sexual foram pautadas em preconceitos sutis, cada vez mais presentes na sociedade, pois ninguém consegue admitir que tenha preconceitos, mesmo justificando que a falta de informações e os valores arraigados dificultam um olhar mais coerente acerca das diferenças, sobretudo quando se trata das múltiplas sexualidades e das identidades de gênero. Assim, o estranhamento e a não aceitação da diversidade sexual que caracterizam o preconceito manifesto estão sendo substituídas pela tolerância e respeito à diversidade sexual, que, embora, à primeira vista, demonstrem certo avanço, deixam camuflados o não (re)conhecimento e a marginalização da diversidade sexual sob a perspectiva do preconceito sutil.

Ainda que se tente omitir, a homofobia está presente no cenário escolar, principalmente através de injúrias e bullying contra os sujeitos que destoam do padrão heteronormativo. Contudo, as representações acerca da homofobia se mostram limitadas, o que contribui para a banalização dos insultos, piadinhas e apelidos pejorativos (entre outros) manifestados no cotidiano escolar, mas que não costumam ser problematizados, objetivando-se evitar a exclusão de jovens LGBT ou afins. Nesse caminho, cabe questionar: Quais ações interventivas podem contribuir para o (re)conhecimento da diversidade sexual e a desconstrução da homofobia?

Esses questionamentos evidenciam os desafios que a diversidade sexual e a homofobia engendram no contexto escolar. Destarte, tais indagações são bastante difíceis de responder e, sobretudo, de colocar em prática, porém, se destacam algumas considerações para o (re)conhecimento da diversidade sexual e desconstrução das práticas

${ }^{2}$ A exemplo do Curso de Licenciatura em Ciências Biológicas da Universidade Federal de Sergipe/ UFS que já incluiu a disciplina "Corpo, Gênero e Sexualidade" como obrigatória. homofóbicas sutis. A saber, a criação de disciplinas ${ }^{2}$ em cursos de formação inicial e continuada, projetos de extensão (nas universidades), bem como a realização de atividades acadêmicas e pesquisas voltadas para essa área, aliadas à busca de parcerias com escolas e o movimento LGBT, podem constituir meios significativos para possibilitar conhecimentos e estimular a discussão desses assuntos no ambiente escolar. Nesse rumo, salienta-se a relevância da abordagem das temáticas diversidade sexual, sexualidade e gênero nas licenciaturas, de modo que os/as educadores/as sejam 
instigados/as a rever suas representações, frequentemente compostas por preconceitos. E, assim, possam adotar modalidades didáticas que permitam acolher a multiplicidade de sujeitos no ambiente escolar, pautando-se nos direitos humanos, na equidade, no reconhecimento e contribuindo para a desconstrução de todas as formas sutis de preconceitos e discriminações.

\section{Referências}

ALVES-MAZZOTTI, Alda Judith. "Representações sociais: aspectos teóricos e aplicações à Educação". Revista Múltiplas Leituras, v. 1, n. 1, p. 18-43, jan./jun. 2008.

ARRUDA, Ângela. "O ambiente natural e seus habitantes no imaginário brasileiro". In: (Org.). Representando a alteridade. 2.ed. Petrópolis: Vozes, 2002. p. 17-46.

BARDIN, Laurence. Análise de conteúdo. Lisboa: Edições 70 , 2011.

BORRILLO, Daniel. "A homofobia”. In: LIONÇO, Tatiana; DINIZ, Debora (Orgs.). Homofobia \& Educação: um desafio ao silêncio. Brasília: Letras Livres; EDUnB, 2009. p. 15-46.

. Homofobia: história e crítica de um preconceito. Belo Horizonte: Autêntica, 2010.

BRASIL. Relatório sobre violência homofóbica no Brasil: o ano de 2011 . Brasília: Distrito Federal, 2012.

CAVALEIRO, Maria Cristina. "Escola e sexualidades: alguns apontamentos para reflexões". In: FIGUEIRÓ, Mary Neide Damico (Org.). Educação sexual: em busca de mudanças. Londrina: UEL, 2009. p. 153-169.

CROCHIK, José Leon. Preconceito, indivíduo e cultura. 3.ed. São Paulo: Casa do Psicólogo, 2006.

DINIS, Nilson Fernandes. "Educação e diversidade sexual: interfaces Brasil/Canadá". Revista Educação e Cultura Contemporânea, v. 9, n. 18, p. 75-96, 2012.

FLEURY, Alessandra Ramos Demito; TORRES, Ana Raquel Rosas. Homossexualidade e preconceito: o que pensam os futuros gestores de pessoas. Curitiba: Juruá, 2010.

HENRIQUES, Ricardo; BRANDT, Maria Elisa Almeida; JUNQUEIRA, Rogério Diniz; CHAMUSCA, Adelaide (Orgs.). Gênero e diversidade sexual na escola: reconhecer diferenças e superar preconceitos. Brasília: CADERNOS SECAD, 2007.

JODELET, Denise. "Représentations Sociales: un Domaine en Expansion". In: ___ (Ed.). Les Représentations Sociales. Tradução: Tarso Bonilha Mazzotti. Revisão Técnica: Alda Judith Alves-Mazzotti. Rio de Janeiro: UFRJ - Faculdade de Educação, 1993, p. 31-61. Disponível em: http:// docplayer.com.br/36945-Representacoes-sociais-umdominio-em-expansao-denise-jodelet.html. 
JOVCHELOVITCH, Sandra. "Vivendo a vida com os outros: intersubjetividade, espaço público e representações sociais". In: GUARESCHI, Pedrinho A.; JOVCHELOVITCH, Sandra (Orgs.). Textos em representações sociais. 10.ed. Petrópolis: Vozes, 2008. p. 63-85.

JUNQUEIRA, Rogério Diniz. "Educação e homofobia: o reconhecimento da diversidade sexual para além do multiculturalismo liberal". In:_ (Org.). Diversidade sexual na educação: problematizações sobre a homofobia nas escolas. Brasília: Ministério da Educação. Secretaria de Educação Continuada, Alfabetização e Diversidade. Brasília: UNESCO, 2009. p. 367-444.

KAMEL, Luciana; PIMENTA, Cristina. Diversidade sexual nas escolas: o que os profissionais de educação precisam saber. Rio de Janeiro: ABIA, 2008.

KOEHLER, Sonia Maria Ferreira. "A representação social da homofobia na cidade de Lorena/SP". Revista Diálogo Educacional, Curitiba, v. 9, n. 28, p. 587-604, set./dez. 2009.

LIMA, Marcus Eugênio Oliveira. "Preconceito". In: LIMA, Marcus Eugênio Oliveira; PEREIRA, Marcos Emanoel; CAMINO, Leoncio; TORRES, Ana Raquel Rosas (Orgs.). Psicologia social: temas e teorias. Brasília: Technopolitik, 2011. p. 451-500.

LIMA, Marcus Eugênio Oliveira; VALA, Jorge. "As novas formas de expressão do preconceito e do racismo". Estudos de Psicologia, Natal, v. 9, n. 3, p. 401-411, 2004.

LOURO, Guacira Lopes. Gênero, sexualidade e educação: uma perspectiva pós-estruturalista. 2.ed. Petrópolis: Vozes, 1997. 179p.

.Pedagogias da sexualidade". In: (Org.). $\mathrm{O}$ corpo educado: pedagogias da sexualidade. 2.ed. Belo Horizonte: Autêntica, 2000. p. 07-34.

"Heteronormatividade e homofobia". In: JUNQUEIRA, Rogério Diniz (Org.). Diversidade sexual na educação: problematizações sobre a homofobia nas escolas. Ministério da Educação. Secretaria de Educação Continuada, Alfabetização e Diversidade. Brasília: UNESCO, 2009. p. 85-94.

MADUREIRA, Ana Flávia do Amaral. Gênero, sexualidade e diversidade sexual na escola: a construção de uma cultura democrática. 2007. Tese (Doutorado) - UnB, Brasília.

MARKOVÁ, Ivana. "The Epistemological Significance of the Theory of Social Representations". Journal for the Theory of Social Behaviour, v. 38, n. 4, 2008.

MINAYO, Maria Cecília de Souza. "O conceito de representações sociais dentro da sociologia clássica". In: GUARESCHI, Pedrinho A.; JOVCHELOVITCH, Sandra (Orgs.). Textos em representações sociais. 10.ed. Petrópolis: Vozes, 2008. p. 89-111.

542 Estudos Feministas, Florianópolis, 25(2): 519-544, maio-agosto/2017 
MOSCOVICl, Serge. Representações sociais: investigações em psicologia social. 7.ed. Petrópolis: Vozes, 2010.

NARDI, Henrique Caetano. "Homophobia or Sexism? A systematic Review of Prejudice against Nonheterosexual Orientation in Brazil". International Journal of Psychology, v. 48, n. 5, p. 900-910, 2012.

PRADO, Marco Aurélio Máximo; JUNQUEIRA, Rogério Diniz. "Homofobia, hierarquização e humilhação social". In: VENTURI, Gustavo; BOKANY, Vilma. Diversidade sexual e homofobia no Brasil. São Paulo: Fundação Perseu Abramo, 2011. p. 51-71.

RIOS, Roger Raupp. "Homofobia na perspectiva dos direitos humanos e no contexto dos estudos sobre preconceito e discriminação". In: JUNQUEIRA, Rogério Diniz (Org.). Diversidade sexual na educação: problematizações sobre a homofobia nas escolas. Ministério da Educação. Secretaria de Educação Continuada, Alfabetização e Diversidade. Brasília: UNESCO, 2009. p. 53-84.

SEFFNER, Fernando. "Equívocos e armadilhas na articulação entre diversidade sexual e políticas de inclusão escolar". In: JUNQUEIRA, Rogério Diniz (Org.). Diversidade sexual na educação: problematizações sobre a homofobia nas escolas. Ministério da Educação, Secretaria de Educação Continuada. Alfabetização e Diversidade. Brasília: UNESCO, 2009. p. 125-140.

"Sigam-me os bons: apuros e aflições nos enfrentamentos ao regime da heteronormatividade no espaço escolar". Educação e Pesquisa, v. 39, n. 1, p. 145-159, 2013.

SILVA JUNIOR, Jonas Alves da. Rompendo a mordaça: representações sociais de professores e professoras do ensino médio sobre homossexualidade. 2010. Tese (Doutorado) - Faculdade de Educação, USP, São Paulo.

TOSSO, Melani Penna. Formación del Profesorado en la Atención a la Diversidad Afectivo-Sexual. 2012. Tesis (Doctoral) - Faculdad de Educación, Universidad Complutense de Madrid, Madrid.

[Recebido em 18/06/2015, reapresentado em $24 / 03 / 2016$ e aprovado em 13/04/2016]

\section{Representations of Teachers about Sexual Diversity and Homophobia}

Abstract: The social representations that teachers have about sexual diversity influence the construction and deconstruction of prejudice at school. Thus, this qualitative study aimed to analyze the social representations of middle and high school teachers about sexual diversity and homophobia. For this, we used the thematic content analysis method. The results showed that teachers' representations are based on social patterns about sexual diversity, which generate subtle prejudices and contribute to homophobia in school. Therefore, there is need for valuable 
information on these issues, enabling teachers to promote pedagogical actions that contribute to recognition of sexual diversity.

Key words: Representations; Sexual diversity; Prejudices.

Elaine de Jesus Souza (elaine.js.sd@hotmail.com) é doutoranda em Educação pela Universidade Federal do Rio Grande do Sul/UFRGS; bolsista CNPq e mestra em Psicologia Social pela Universidade Federal de Sergipe/UFS. É, também, membro do Grupo de Pesquisa Gênero, Sexualidade e Estudos Culturais/GESEC/UFS/CNPq.

Joilson Pereira da Silva (joilsonp@hotmail.com) é doutor em Psicologia pela Universidade Complutense de Madri, Espanha, e pós-doutor em Psicologia pela Universidade Autônima de Barcelona, Espanha. Mestre e graduado em Psicologia (UFPB), graduado em Estudos Sociais e Geografia (UEPB). É professor associado da Universidade Federal de Sergipe e professor credenciado do Programa de Pós-Graduação em Psicologia. Atua como membro pesquisador do Grupo de Pesquisas VIPAT (Violencia en la Pareja y en el Trabajo) do Departamento de Psicologia Social da Universidade Autônoma de Barcelona. Desenvolve pesquisas nas áreas de Educação e desenvolvimento psicossocial de surdos, inclusão social, diversidade sexual e violência.

Claudiene Santos (claudienesan@gmail.com) é professora adjunta do Departamento de Biologia da Universidade Federal de Sergipe (UFS) e líder do Grupo de Pesquisa Gênero, Sexualidade e Estudos Culturais (GESEC/UFS/CNPq).

544 Estudos Feministas, Florianópolis, 25(2): 519-544, maio-agosto/2017 